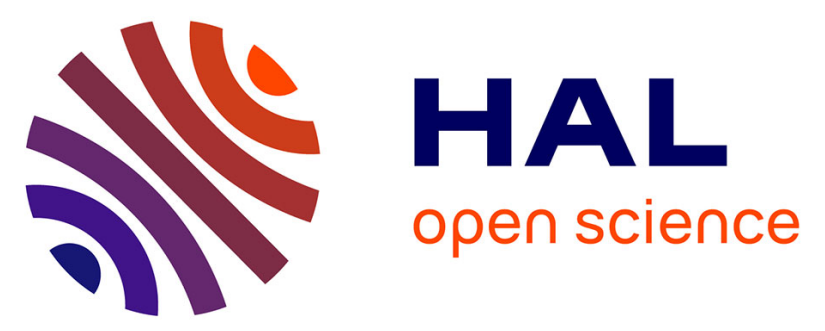

\title{
Influence of the hydrocarbon chain length of imidazolium-based ionic liquid on the dispersion and stabilization of double-walled carbon nanotubes in water
}

Kenza Raiah, Abdelkader Djalab, Amel Hadj-Ziane-Zafour, Brigitte Soula, Anne-Marie Galibert, Emmanuel Flahaut

\section{To cite this version:}

Kenza Raiah, Abdelkader Djalab, Amel Hadj-Ziane-Zafour, Brigitte Soula, Anne-Marie Galibert, et al. Influence of the hydrocarbon chain length of imidazolium-based ionic liquid on the dispersion and stabilization of double-walled carbon nanotubes in water. Colloids and Surfaces A: Physicochemical and Engineering Aspects, 2015, vol. 469, pp. 107-116. 10.1016/j.colsurfa.2015.01.015 . hal-01475298

\author{
HAL Id: hal-01475298 \\ https://hal.science/hal-01475298
}

Submitted on 23 Feb 2017

HAL is a multi-disciplinary open access archive for the deposit and dissemination of scientific research documents, whether they are published or not. The documents may come from teaching and research institutions in France or abroad, or from public or private research centers.
L'archive ouverte pluridisciplinaire $\mathbf{H A L}$, est destinée au dépôt et à la diffusion de documents scientifiques de niveau recherche, publiés ou non, émanant des établissements d'enseignement et de recherche français ou étrangers, des laboratoires publics ou privés. 


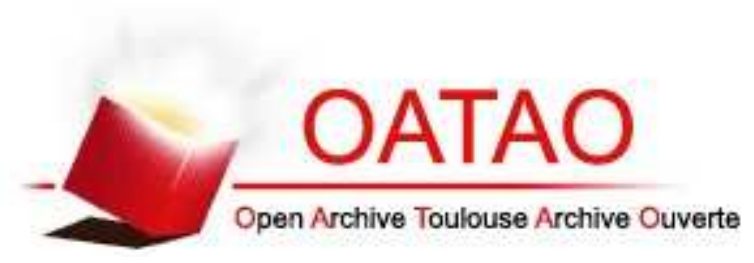

\section{Open Archive TOULOUSE Archive Ouverte (OATAO)}

OATAO is an open access repository that collects the work of Toulouse researchers and makes it freely available over the web where possible.

This is an author-deposited version published in : http://oatao.univ-toulouse.fr/ Eprints ID : 16786

To link to this article : DOI : 10.1016/j.colsurfa.2015.01.015

URL : http://dx.doi.org/10.1016/j.colsurfa.2015.01.015

To cite this version : Raiah, Kenza and Djalab, Abdelkader and Hadj-Ziane-Zafour, Amel and Soula, Brigitte and Galibert, AnneMarie and Flahaut, Emmanuel Influence of the hydrocarbon chain length of imidazolium-based ionic liquid on the dispersion and stabilization of double-walled carbon nanotubes in water. (2015) Colloids and Surfaces A: Physicochemical and Engineering Aspects, vol. 469. pp. 107-116. ISSN 0927-7757

Any correspondence concerning this service should be sent to the repository administrator: staff-oatao@ listes-diff.inp-toulouse.fr 


\title{
Influence of the hydrocarbon chain length of imidazolium-based ionic liquid on the dispersion and stabilization of double-walled carbon nanotubes in water
}

\author{
Kenza Raiah ${ }^{\mathrm{a}}$, Abdelkader Djalab ${ }^{\mathrm{a}}$, Amel Hadj-Ziane-Zafour ${ }^{\mathrm{a}}$, Brigitte Soula ${ }^{\mathrm{b}}$, \\ Anne-Marie Galibert ${ }^{\mathrm{b}}$, Emmanuel Flahaut ${ }^{\mathrm{b}, \mathrm{c}, *}$ \\ a Laboratoire de Génie Chimique, Université Saad Dahlab, Route de Soumaa, B.P. 270 Blida, Algeria \\ ${ }^{\mathrm{b}}$ Université de Toulouse, UPS, INP, Institut Carnot Cirimat, 118, Route de Narbonne, F-31062 Toulouse cedex 9, France \\ ${ }^{\mathrm{c}}$ CNRS, Institut Carnot Cirimat, F-31062 Toulouse, France
}

H I G H L I G H T S

- Synthesis of imidazolium-based ionic liquids from natural compounds (fatty acids).

- Stabilization of $50 \mathrm{mg} / \mathrm{L}$ double walled carbon nanotubes in water up to 20 days.

- Dispersibility increased with increasing the length of the hydrocarbon chain.
G R A P H I C A L A B S T R A C T

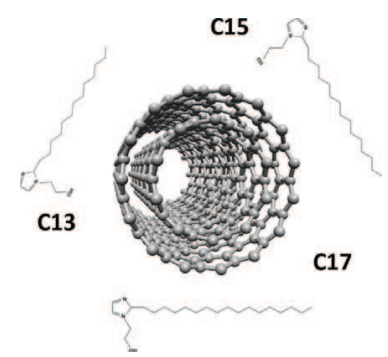

A B S T R A C T

Imidazolium-based ionic liquids with a long hydrocarbon chain 1-methyl-1-ethanol-2-alkylimidazolium iodide ([M-E- $C_{n}$-Im] I, $n=13,15$ and 17) were used for the dispersion of DWCNTs in water. DWCNTs suspensions obtained were stable for more than a month, and no sedimentation was observed. The stability of the suspensions was investigated (measurement of optical density, zeta potential, particle size, viscosity, and TEM images). Monitoring of the absorbance by UV/vis spectrophotometry for 20 days showed that at low concentration $(1 \mathrm{mM})$, the best suspension was obtained with the ionic liquid ([M-E- $\left.\left.\mathrm{C}_{15}-\mathrm{Im}\right] \mathrm{I}\right)$. At higher concentration $(10 \mathrm{mM})$, the dispersion efficiency increased with the length of the hydrocarbon chain. This could be explained by the hydrophobic interaction between the hydrophobic moieties of the ionic liquid and the CNTs. Therefore, we were able to stabilize DWCNTs using a low concentration $(1 \mathrm{mM})$ of imidazolium-based ionic liquids synthesized from natural compounds. This work highlights the potential of imidazolium-based ionic liquids for the preparation of aqueous suspensions of DWCNTs at high concentration with a limited amount of added surfactant $(50 \mathrm{mg} / \mathrm{L}$ of DWCNTs with $50 \mathrm{mg} / \mathrm{L}$ of ionic liquid).

\footnotetext{
* Corresponding author at: CNRS, Institut Carnot Cirimat, F-31062 Toulouse, France. Tel.: +33 561556280 .

E-mail address: flahaut@chimie.ups-tlse.fr (E. Flahaut).

\section{Introduction}

Carbon nanotubes (CNTs), described as such for the first time in 1991, are still of great interest for the scientific community due to their exceptional intrinsic properties (electrical, mechanical and thermal), opening a very wide field of applications for these 
nanomaterials [1-3]. Though carbon nanotubes have promising applications, their insolubility in water and most organic solvents is challenging. This insolubility is explained by both intrinsic hydrophobicity and their strong agglomeration caused by van der Waals interactions and entanglement [4]. Several studies have tried to solve this problem by covalent functionalization methods [5-7] or by adsorption of amphiphilic agents [8-12]. Covalent functionalization using oxidizing acids at high temperature causes defects on the walls of the carbon nanotubes and their length decreases, therefore their electrical and mechanical properties are degraded $[13,14]$. Non-covalent functionalization by adsorption of surfactant or polymers and use of mild ultrasonic treatments, centrifugation and filtration does not disturb the $\pi-\pi$ stacking or the lengths of CNTs, thus, maintaining intrinsic properties of the CNTs [15-17].

Different kinds of surfactants have been used successfully for the dispersion of CNTs, such as the anionic SDS (sodium dodecyl sulphate) [18,19], cationic CTAB (cetyl trimethyl ammonium bromide) $[20,21]$ and non-ionic Triton X-100 [22]. However the nature of the surfactant and its concentration have an important role in the dispersion of CNTs in water and organic media $[23,24]$. Previous work has shown that ionic liquids have a better dispersing efficiency compared to conventional surfactants [25-28]. Some studies have been conducted on imidazolium-based ionic liquids: Kim et al. [29] prepared stable suspensions using an imidazolium-based ionic liquid (1-butyl-3-methylimidazolium tetrafluoroborate) and SWCNTs. SWCNTs suspended by imidazolium-based ionic liquid form a gel, called Bucky gel [30]. Non-covalent functionalization of oxidized single-walled carbon nanotubes by poly imidazoliumbased ionic liquids was also used for the synthesis of gels [31]. SWCNTs dispersed in imidazolium-based ionic liquids [32] have been used as cathode in high-power lithium batteries. A MWCNTs suspension with 1-ethyl-3methylimidazolium tetrafluoroborate in dimethlformamide was used as an immunosensor of myeloperoxidase detection in human serum [33]. A magnetically sensitive material was prepared with SWCNTs and a magnetic ionic liquid (1-butyl-3-methylimdazolium $\left[\mathrm{FeCl}_{4}\right]$ ), which finds applications in biomedical research (such as targeted drug delivery and controlled release, protein separation, cancer treatment) [34]. A method was developed to decorate MWCNTs with noble metal particles (gold) by the means of ionic liquid 1-hexadecyl-3-methylimidazolium bromide [27]. Yang et al. [35] performed a quantitative characterization by UV/vis spectrophotometry of SWCNTs suspensions prepared in ionic liquid 1-N-butylmethylimidazolium hexafluorophosphate.

Di Crescenzo et al. [26] have shown that the ionic liquid with a long hydrocarbon chain 1-hexadecyl-3-vinyl-imidazolium bromide formed a stable homogeneous aqueous dispersions with SWCNTs above its critical micelle concentration. Liu et al. [25] reported that they obtained stable aqueous suspensions of MWCNTs with ionic liquid-type Gemini imidazolium $\left(\left[C_{n}-C_{4}-C_{n}-I m\right] B_{2}\right.$, $n=12,14)$ even at low concentration $(1 \mathrm{mM})$. The binary mixture of 1-tetradecyl-3-methylimidazolium chloride/ethylammonium nitrate successfully dispersed MWCNTs [36]. The ionic liquid with polycyclic aromatic fraction and a long hydrocarbon chain - [n(N-carbazole) alkyl]-3-methylimidazolium bromide yielded good CNTs suspensions in water ( 10 months, at $1 \mathrm{mM})$, showing the combined effects of both a hydrocarbon chain and a carbazole moiety [37]. The adsorption of the imidazolium-based ionic liquid onto SWCNTs was explained by their interaction with low van der Walls forces. Therefore, the electronic properties of SWCNT remained unmodified [38]. Madria et al. [39] have shown that 1-methyl-3alkoxyalkyl and 1-methyl-3-fluoroalkyl imidazolium are relatively nontoxic to human health. Riduan et al. [40] investigated the use of imidazolium salts in several areas of bio-applications, including antitumor, antimicrobial, antioxidant and bioengineering. Imidazolium ionic liquids can be regarded as chemical compounds exhibiting a potential, slight toxicity to the growth and development of the early developmental stages of higher land plants [41]. Ionic liquids produced from the bio compounds choline and amino acids were found to have low toxicity to humans and to the environment [42].

In this context, the goal of this work was to disperse and stabilize DWCNTs in water, using imidazolium-based ionic liquids synthesized from natural material namely fatty acids. We investigated the ability of 1-methyl-1-ethanol-2-alkyl-imidazoline iodide to disperse the DWCNT, as well as the effect of the length of the hydrocarbon chain and concentration. In order to compare the efficiency of the three synthesized ionic liquids we monitored the concentration of CNTs versus time (optical density measurements); we measured the values of zeta potential and viscosity and also used static light diffusion to estimate the size of agglomerates. Finally, transmission electron microscopy observations were also performed in order to evidence de-bundling in the presence of surfactant.

\section{Materials and methods}

\subsection{Materials}

Double-walled carbon nanotubes (DWCNT) were synthesized at the CIRIMAT by catalytic chemical vapour deposition (CCVD) [43]. After extraction by treatment with a concentrated $\mathrm{HCl}$ aqueous solution (removal of catalyst support and unprotected metal nanoparticles), the CNT were recovered, washed and kept in a small volume of deionized water. The DWCNT thus prepared are called "raw wet tubes". Myristic acid (99\%), palmitic acid (99\%) and stearic acid (99\%), N (2-hydroxyethyl) ethylene diamine, ethyl iodide, were purchased from Sigma-Aldrich.

\subsection{Synthesis and characterization of ionic liquids}

Imidazolium-based ionic liquids ([M-E- $\left.\mathrm{C}_{n}-\mathrm{Im}\right] \mathrm{I}, n=13,15$ or 17 ) were synthesized by the reaction between the corresponding natural fatty acid with $\mathrm{N}$ (2-hydroxyethyl) ethylene diamine (Fig. 1). All the reagents were in the same molar ratio. The mixture was heated in toluene for $8 \mathrm{~h}$ with stirring and the water formed was removed azeotropically using a Dean-Stark apparatus. Resulting product was cooled and filtered and the solvent evaporated. The solid was precipitated by adding 1-butanol and then recrystallized from ethanol. The precipitated solid and ethyl iodide were heated by refluxing in isopropanol for $4 \mathrm{~h}$, the resulting product was filtered and the solvent evaporated. The solid was precipitated by adding petroleum ether $[44,45]$. We obtained a good yield (91.5\%) in agreement with those already published ((89\%) [46], (92.1\%) [44]). The characterization of the synthesized products was carried out by FT-IR, GC-MS, ${ }^{1} \mathrm{H}$ NMR and ${ }^{13} \mathrm{C}$ NMR analysis, and by measurement of CMC (critical micelle concentration).

The Fourier transmission infra-red (FT-IR) measurements were made on Perkin Elmer Spectrometer operating with UATR (Universal attenuation total reflectance), spectral range between 4000 and $650 \mathrm{~cm}^{-1}$, at $4 \mathrm{~cm}^{-1}$ of resolution. The gas chromatography coupled with mass spectrometry (GC-MS) analysis was performed with a Perkin Elmer Clarus 500, RTX-5MS equipped with a capillary GC column ( $60 \mathrm{~m}, 0.25 \mathrm{~mm}, 0.25 \mu \mathrm{m})$, and the system was heated from 100 to $290^{\circ} \mathrm{C}$ with a heating rate of $8{ }^{\circ} \mathrm{C} / \mathrm{min}$ and kept at $290^{\circ} \mathrm{C}$ for $10 \mathrm{~min}$. The temperature of the injector and detector were $250^{\circ} \mathrm{C}$ and $200^{\circ} \mathrm{C}$, respectively. The characterizations by ${ }^{1} \mathrm{H}$ NMR and ${ }^{13} \mathrm{C}$ NMR were carried out using a Brüker advance ( $500 \mathrm{MHz}$ ) equipped with a TCI probe type (Triple Cryoprobe Inverse); the samples were dissolved in $\mathrm{CDCl}_{3}$. The determination of the critical micellar 

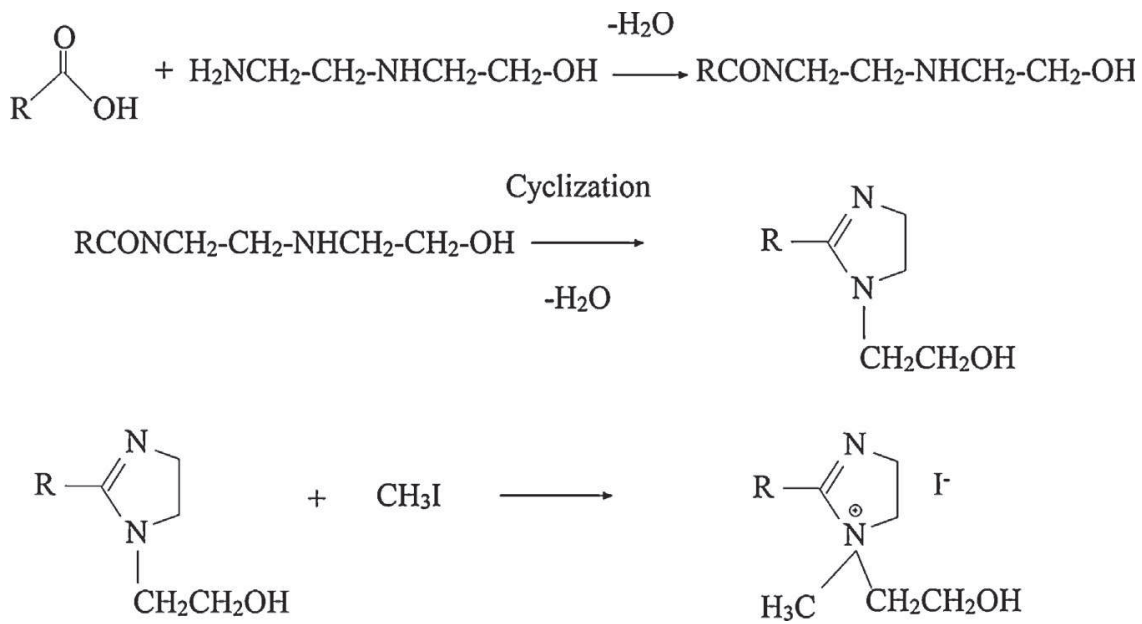

Fig. 1. General scheme for the synthesis reactions of the ionic liquids.

concentration (CMC) was performed by conductivity measurements (Hanna instruments, EC215).

The FT-IR spectra of the three ionic liquids are shown in Fig. 2. The presence of the band at $2922 \mathrm{~cm}^{-1}$ corresponds to $\mathrm{CH}_{3}$ and $\mathrm{CH}_{2}$ groups. The presence of a strong band at $3392 \mathrm{~cm}^{-1}$ indicates the formation of primary amine. In addition, the appearance of a band at $1642 \mathrm{~cm}^{-1}$ indicates the formation of the amide $(C=N)$ and is an evidence of the formation of the imidazoline ring [46]. Mass spectra data were analysed using the NIST MS Search library, and the following spectral profiles were obtained with MS (m/z \%): 74 (99), 84 (92), 87 (77), 43 (61), 56 (58), 44 (45), 128 (43), 41 (39), 55 (32) and 141 (26) (Fig. 3) [46].

The characterization by ${ }^{1} \mathrm{H}$ NMR has given the spectra show in Fig. 4. Identification of the peaks is: $\delta 3.04 \mathrm{ppm}(t, 2 \mathrm{H}$, $\left.-\mathrm{C}=\mathrm{N}-\mathrm{C}-\mathrm{CH}_{2}-\mathrm{N}-\right), \delta 3.38 \mathrm{ppm}\left(\mathrm{t}, 2 \mathrm{H},-\mathrm{CH}_{2}-\mathrm{C}-\mathrm{OH}\right), \delta 3.71 \mathrm{ppm}$ $\left(t, 2 \mathrm{H},-\mathrm{C}=\mathrm{N}-\mathrm{CH}_{2}-\right), \delta 2.21 \mathrm{ppm}\left(t, 2 \mathrm{H},-\mathrm{N}=\mathrm{C}-\mathrm{CH}_{2}-\right)$. In Fig. 5 are shown the ${ }^{13} \mathrm{C}$ NMR spectra, indicating the presence of peaks $\delta$ $173.80 \mathrm{ppm}(-\mathrm{N}=\mathrm{C}-\mathrm{N}-)$ and $\delta 60.48 \mathrm{ppm}(-\mathrm{C}-\mathrm{OH})$. The main difference between the three spectra is around $3 \mathrm{ppm}$ and corresponds to impurities (residues of reactants); the signals expected for our compounds are well identified, although ${ }^{1} \mathrm{H}$ NMR does not give any information about the aliphatic chain length.

Fig. 6 shows the variation of the electrical conductivity as a function of the concentration for the three ionic liquids. These curves allowed us to determine the values of the $\mathrm{CMC}$ for each ionic liquid. The CMC was close to $0.8 \mathrm{mM}$ for the three compounds (the CMC is the concentration at which the slope changes, it was determined using the first derivative).

\subsection{Dispersion of carbon nanotubes}

DWCNT suspensions were prepared in deionized water alone. For each ionic liquid, a stock solution was also prepared in deionized water, under magnetic stirring for $4 \mathrm{~h}$, in order to ensure the dissolution of each surfactant. The mixture of the two stock dispersion/solution (DWCNT and surfactant) was designed to obtain $10 \mathrm{ml}$ suspensions of DWCNT at a concentration of $50 \mathrm{mg} / \mathrm{L}$, and the three ionic liquids at concentrations equal to $1,1.5$ and $10 \mathrm{mM}$. DWCNT suspensions obtained were mixed in an ultrasonic bath (Bioblock T570, $35 \mathrm{KHz}, 160 \mathrm{~W}$ ) for $10 \mathrm{~min}$, then using an ultrasonic probe (Vibra Cell Model 75 042, $20 \mathrm{kHz}, 500 \mathrm{~W}$ ) for $30 \mathrm{~min}$ at 25\% amplitude with a pulse of $5 \mathrm{~s}$ on and $5 \mathrm{~s}$ off, in order to avoid overheating. Our choice of a high concentration of $50 \mathrm{mg} / \mathrm{L}$ is justified by further work related to the environmental impact assessment of such suspensions which will be required in order to compare the performance of these Imidazolium-based dispersing agents with our earlier work with DWCNTs involving cellulose derivatives such as carboxymethylcellulose [47,48] or xanthan derivatives [17].

\subsection{Characterization of suspensions}

DWCNT suspensions were characterized by UV/vis absorption (Varian, Cary 300). The absorbance measurements were performed from 400 to $900 \mathrm{~nm}$, immediately after preparation and following 20-day sedimentation. Zeta potential measurements were performed with zetasizer (Model ZEN 3691, Malvern Instruments), using suspensions centrifuged at $1600 \mathrm{rpm}$ for $30 \mathrm{~min}$. The supernatant was separated and then left to settle down for $24 \mathrm{~h}$. No sedimentation could be observed within $24 \mathrm{~h}$. The rate of viscosity versus shear rate was determined with a rheometer (Anton Paar Physica, Germany), operating with a concentric cylinder, and connected to a water bath in order to ensure a constant temperature of $25^{\circ} \mathrm{C}$. Size measurements of dispersed colloids were performed by the technique of static light diffusion (SZ-100, Horiba Scientific), the sizes were measured for $48 \mathrm{~h}$ at regular time intervals. DWCNT suspensions were also characterized by transmission electron microscopy (JEOL $1400 \mathrm{TEM}$ ), operated at $120 \mathrm{kV}$. The samples were prepared by pipetting and dropping a few drops of suspension on 400 mesh Lacey Carbon copper grids, purchased from Agar Scientific.

\section{Results and discussion}

Characterization of DWCNT suspensions was performed by UV/vis spectrophotometry. Although individual CNTs may be UV-vis active in the measurement range $(400-900 \mathrm{~nm})$, there is no absorption band for bundled CNTs [12,25]. Fig. 7 represents the absorbance of the DWCNT suspensions at $50 \mathrm{mg} / \mathrm{L}$ with the three ionic liquids ([M-E- $\left.C_{n}-\mathrm{Im}\right] \mathrm{I}, n=13,15$ and 17 ) at a concentration of $10 \mathrm{mM}$, as well as prepared in deionized water only (no surfactant). Although we did not deserve any maximum absorbance band corresponding to CNTs, the effect of the addition of a surfactant was rather clear in terms of increased absorbance. As the ionic liquids do not have any absorption band within the analysed range, the absorption can only be attributed to CNTs.

The variation of the absorbance as a function of time (20 days) for the DWCNT suspensions prepared with the three ionic liquids at a molar concentration of $1 \mathrm{mM}, 1.5 \mathrm{mM}$ and $10 \mathrm{mM}$ is shown in Fig. 8. The absorbance measurements were performed at $500 \mathrm{~nm}$ $[22,49]$. According to our data, at 1 and $1.5 \mathrm{mM}$ concentrations, we obtained an almost identical absorbance with the two ionic liquids $\left[\mathrm{M}-\mathrm{E}-\mathrm{C}_{15}-\mathrm{Im}\right] \mathrm{I}$ and $\left[\mathrm{M}-\mathrm{E}-\mathrm{C}_{17}-\mathrm{Im}\right] \mathrm{I}$. The low concentrations (1 mM 


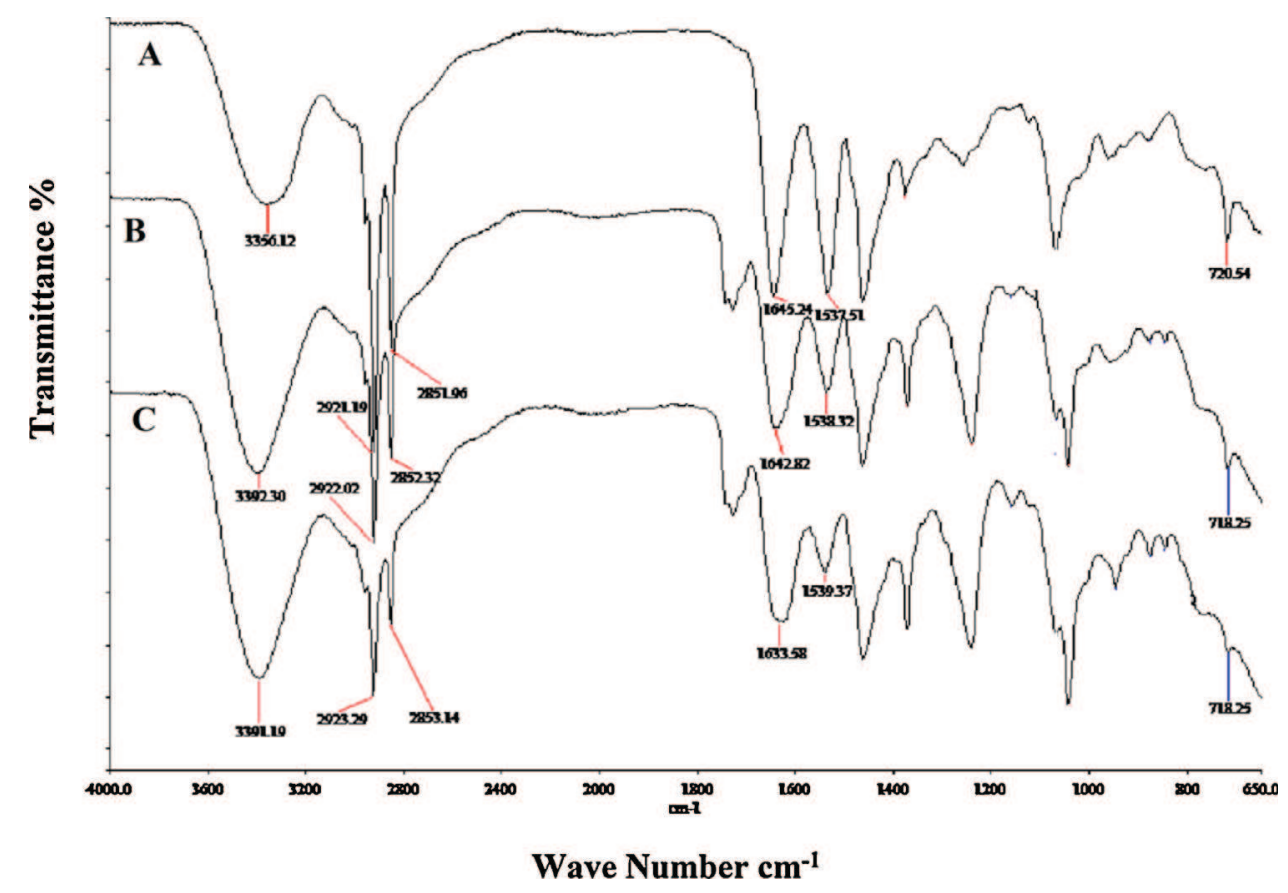

Fig. 2. FT-IR spectra of (A) [M-E- $\left.C_{13}-I m\right] I,(B)\left[M-E-C_{15}-I m\right] I$ and (C) [M-E- $\left.C_{17}-I m\right] I$.

(a) $2854(20.436) \mathrm{Cm}(2854-(2878+2796))$

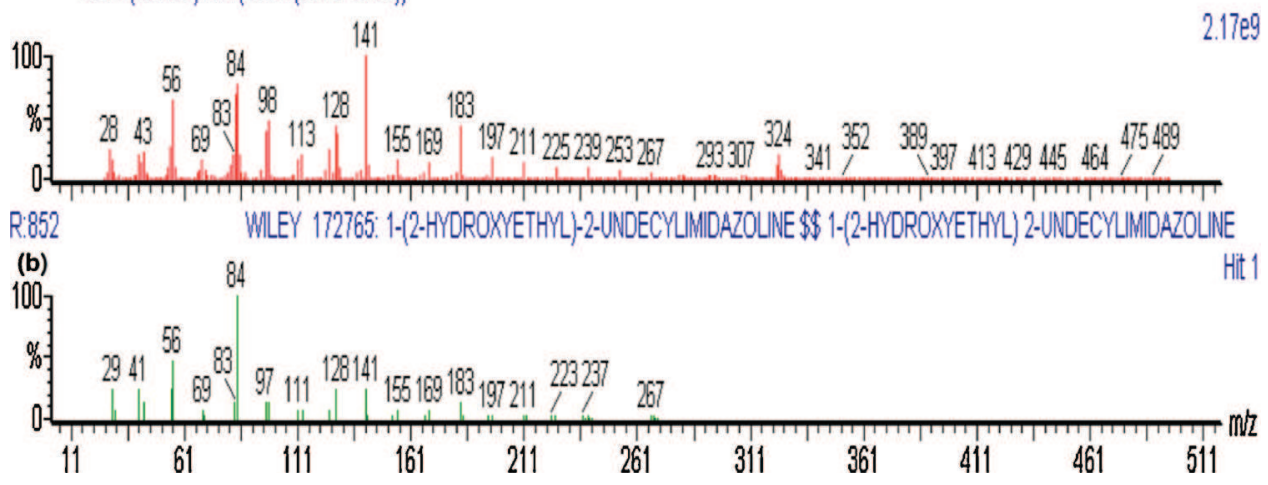

Fig. 3. Mass spectra of (a) [M-E- $\left.C_{15}-I m\right]$ I, compared to (b) data from NIST MS Search library (as an example).
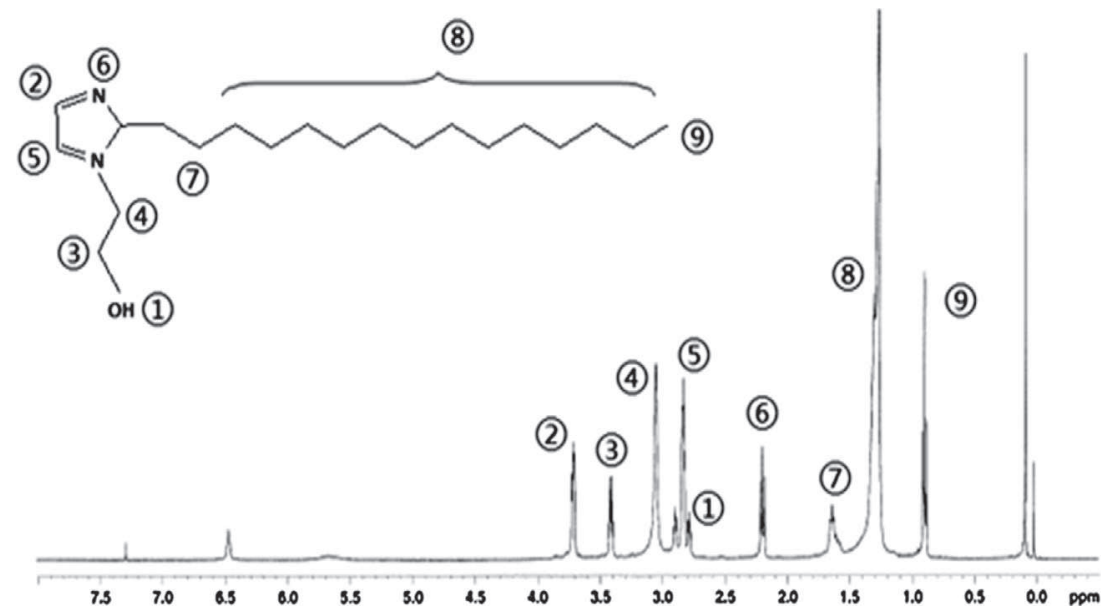

Fig. 4. ${ }^{1} \mathrm{H}$ NMR spectra of $\left[\mathrm{M}-\mathrm{E}-\mathrm{C}_{15}-\mathrm{Im}\right] \mathrm{I}$ (as an example). 


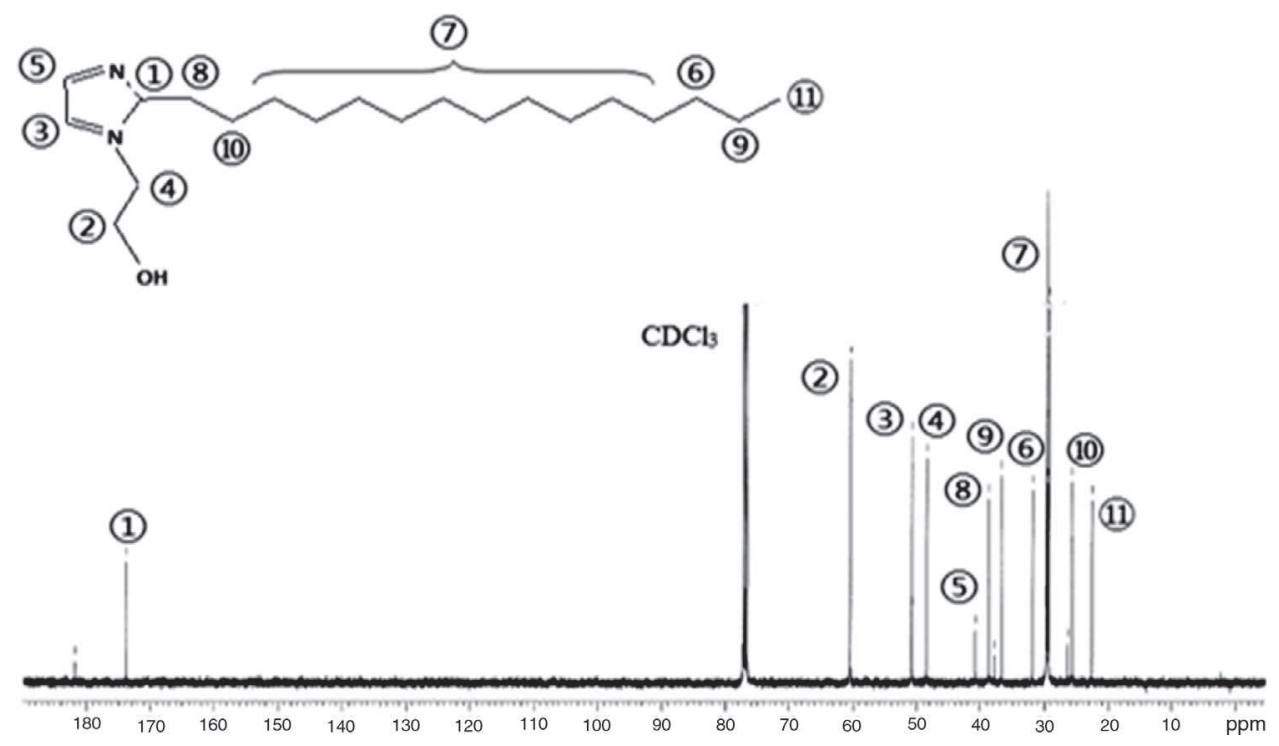

Fig. 5. ${ }^{13} \mathrm{C}$ NMR spectra of [M-E- $\left.\mathrm{C}_{15}-\mathrm{Im}\right] \mathrm{I}$ (as an example).

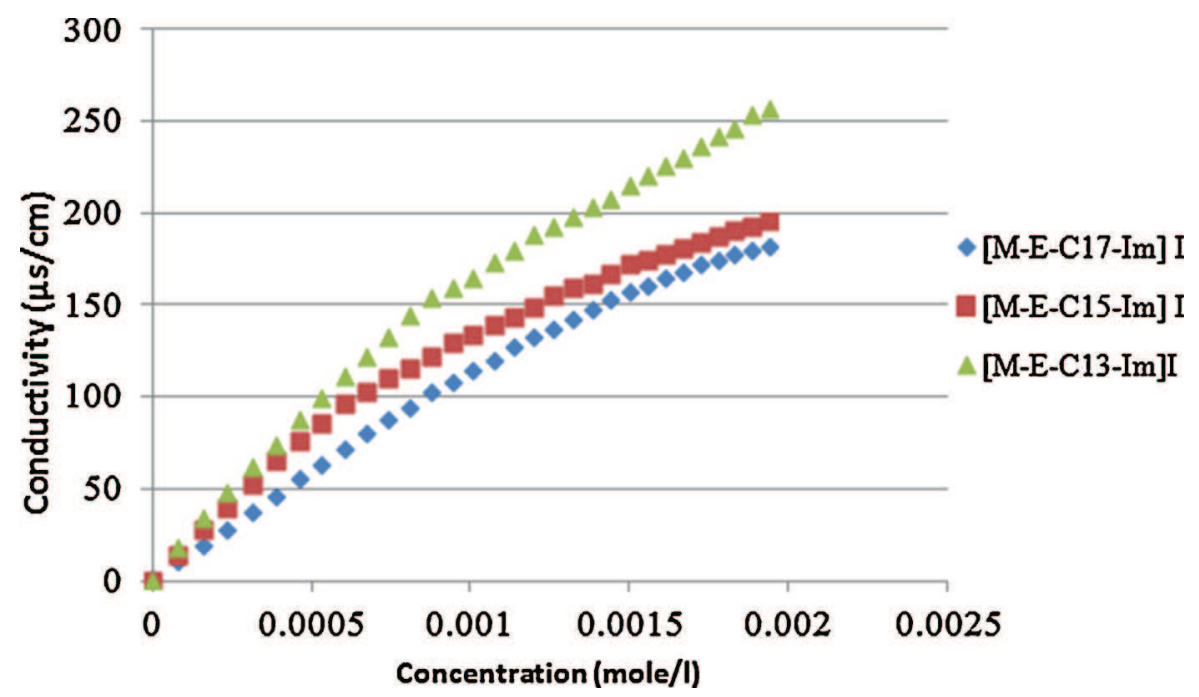

Fig. 6. Variation of the electrical conductivity as a function of the concentration of ionic liquid.

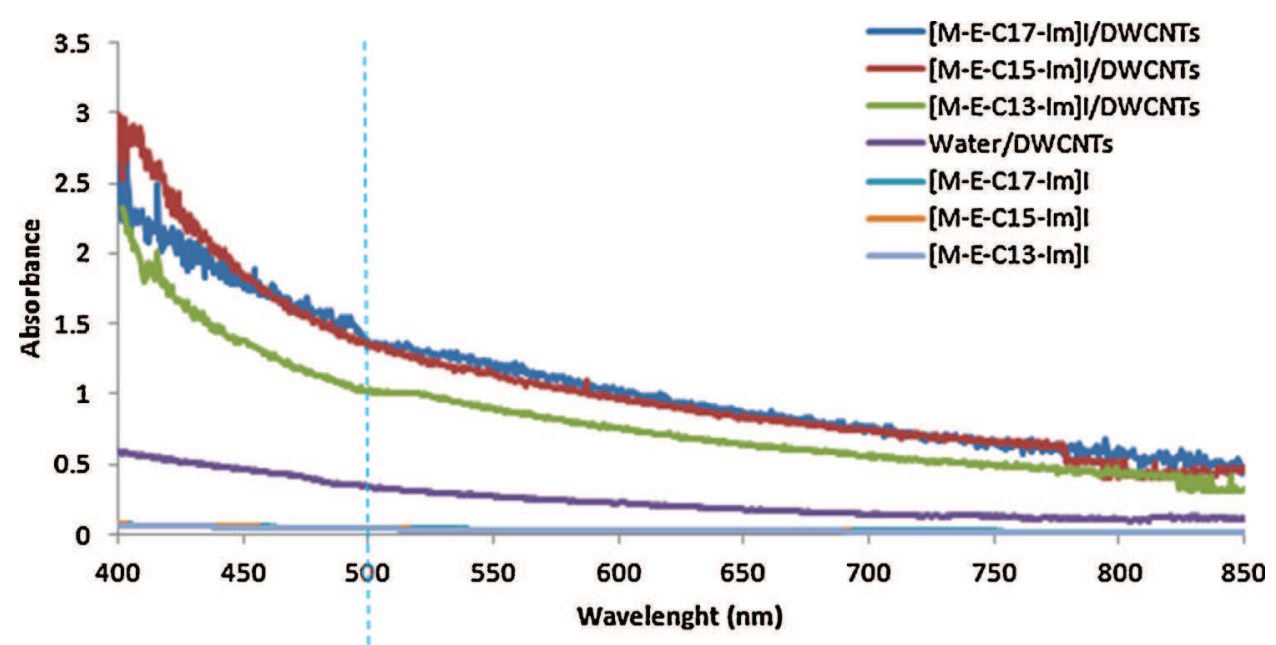

Fig. 7. UV/vis spectra of ionic liquids [M-E- $\left.\mathrm{C}_{13}-\mathrm{Im}\right] \mathrm{I}$, [M-E- $\left.\mathrm{C}_{15}-\mathrm{Im}\right] \mathrm{I}$, [M-E- $\left.\mathrm{C}_{17}-\mathrm{Im}\right] \mathrm{I}$ at $10 \mathrm{mM}$ and DWCNT suspensions with ionic liquids $\left[\mathrm{M}-\mathrm{E}-\mathrm{C}_{13}-\mathrm{Im}\right] \mathrm{I}$, [M-E- $\left.\mathrm{C}_{15}-\mathrm{Im}\right] \mathrm{I}$, $\left[\mathrm{M}-\mathrm{E}-\mathrm{C}_{17}-\mathrm{Im}\right] \mathrm{I}$ and water only (immediately after preparation). 

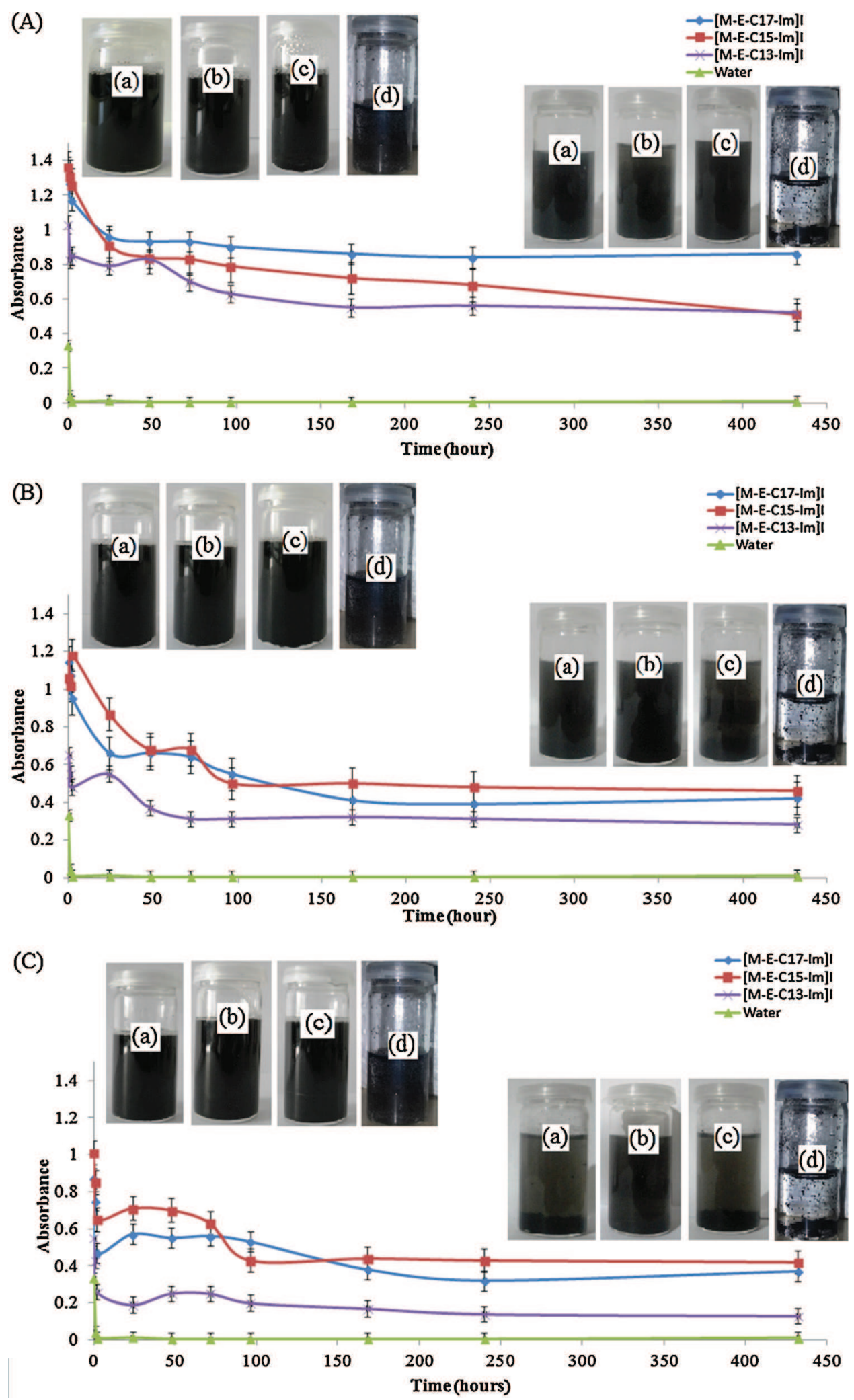

Fig. 8. UV/vis absorbance intensity versus time of DWCNTs $\left(50 \mathrm{mg} / \mathrm{L}\right.$ ) in ionic liquids (a) [M-E-C $\left.\mathrm{C}_{13}-\mathrm{Im}\right] \mathrm{I},(\mathrm{b})\left[\mathrm{M}-\mathrm{E}-\mathrm{C}_{15}-\mathrm{Im}\right] \mathrm{I}$, (c) [M-E-C $\left.\mathrm{C}_{17}-\mathrm{Im}\right] \mathrm{I}$ and (d) deionized water alone at a concentration of (A) $10 \mathrm{mM},(B) 1.5 \mathrm{mM}$ and (C) $1 \mathrm{mM}$, up to 20 days.

and $1.5 \mathrm{mM}$ ) are just above the critical micelle concentration of the three ionic liquids (CMC is equal to ca. $0.8 \mathrm{mM}$, evaluated from electrical conductivity measurements) and did not lead to good dispersion and stability. This phenomenon can be explained by the fact that the dispersion of the nanotubes with the amphiphiles is only possible above the limit of the CMC [50,51]. Thus, the dispersing power of the ionic liquids close to the CMC was low compared to the concentration of $10 \mathrm{mM}$ (10 times more).

At the concentration of $10 \mathrm{mM}$ of ionic liquid, the absorbance of suspensions increased with increasing the length of the 


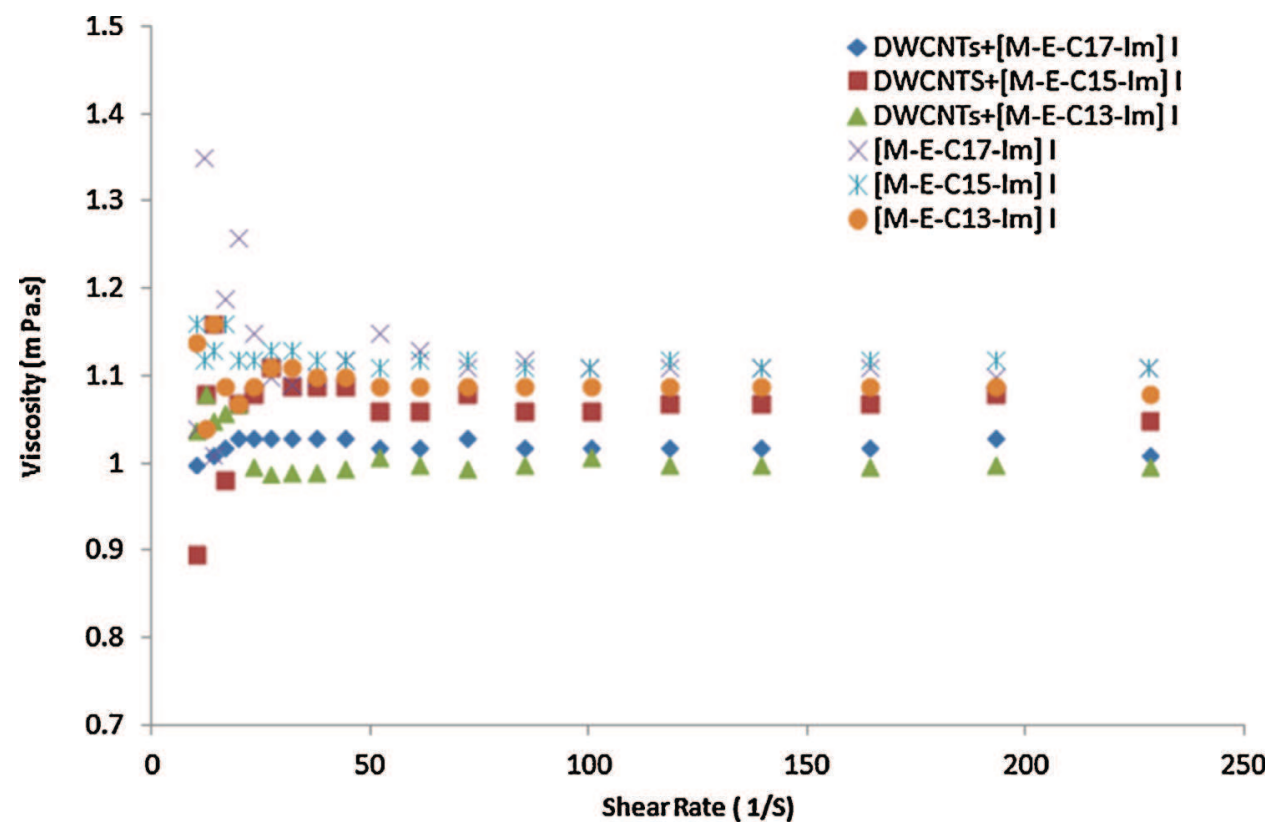

Fig. 9. Variation of the viscosity versus shear rate for the three ionic liquids of $1 \mathrm{mM}$ and DWCNT ( $50 \mathrm{mg} / \mathrm{L}$ ) suspensions with the three ionic liquids.

hydrophobic chain. The best value was obtained with the ionic liquid [M-E- $\mathrm{C}_{17}-\mathrm{Im}$ ] I. Similarly the absorbance of the suspension prepared with [ME-C15-Im] I was higher than the one prepared with [ME-C13-Im] I. The three ionic liquids have a homologous structure. The only difference lies in the length of the hydrocarbon chain $(C=13,15$ and 17). The increase in dispersing efficiency with increasing the length of the hydrocarbon chain can be explained by the increase in hydrophobic interaction between the hydrocarbon chains of ionic liquids and DWCNTs [25,52] (generally, because CNTs have a very hydrophobic surface, the hydrocarbon chains tend to be strongly adsorbed $[53,54]$ ). A better interface between the hydrophobic chain and the nanotubes means a higher stability of the adsorption and less possible exchanges with the surrounding solvent. In this comparison, there is probably no modification of the steric hindrance due to the small differences in terms of carbon atoms in the alkyl chain. Taking into account the fact that the charge is coming from exactly the same chemical group for the series of ionic liquids, the electrostatic repulsion is not expected to be different. If the difference in chain length was enough to lead to different rates of coverage onto the nanotubes, this should finally lead to a different number of charges and this would finally be in favour of the shorter alkyl chain ionic liquid (C13). Consequently, we assume that the key parameter is the stability of the interaction between the adsorbed ionic liquid and the nanotubes, which is in favour of the longest alkyl chain.

The measurement of zeta potential is important to explain the stability of the colloidal particles in aqueous suspension [28,55].WE measured the zeta potential of DWCNT suspension using the three ionic liquids at the concentration of $1 \mathrm{mM}$ and obtained zeta potential values larger than $40 \mathrm{mV}$. According to Dong et al. [37] the particles with a zeta potential larger than $15 \mathrm{mV}$ in absolute value are considered to be stabilized by electrostatic repulsions. A high positive value of zeta potential indicates the strong adsorption of the ionic liquid to the surface of DWCNTs, leading to stable suspensions due to Coulomb force between the CNTs [25]. Therefore, a high stability of DWCNT suspensions was evidenced. Table 1 illustrates the values of zeta potential of the DWCNT suspensions with the three ionic liquids. The largest value of zeta potential was obtained with the DWCNTs suspension prepared with the ionic liquid [ME- $\left.\mathrm{C}_{15}-\mathrm{Im}\right] \mathrm{I}$, although it is quite similar to the value obtained for

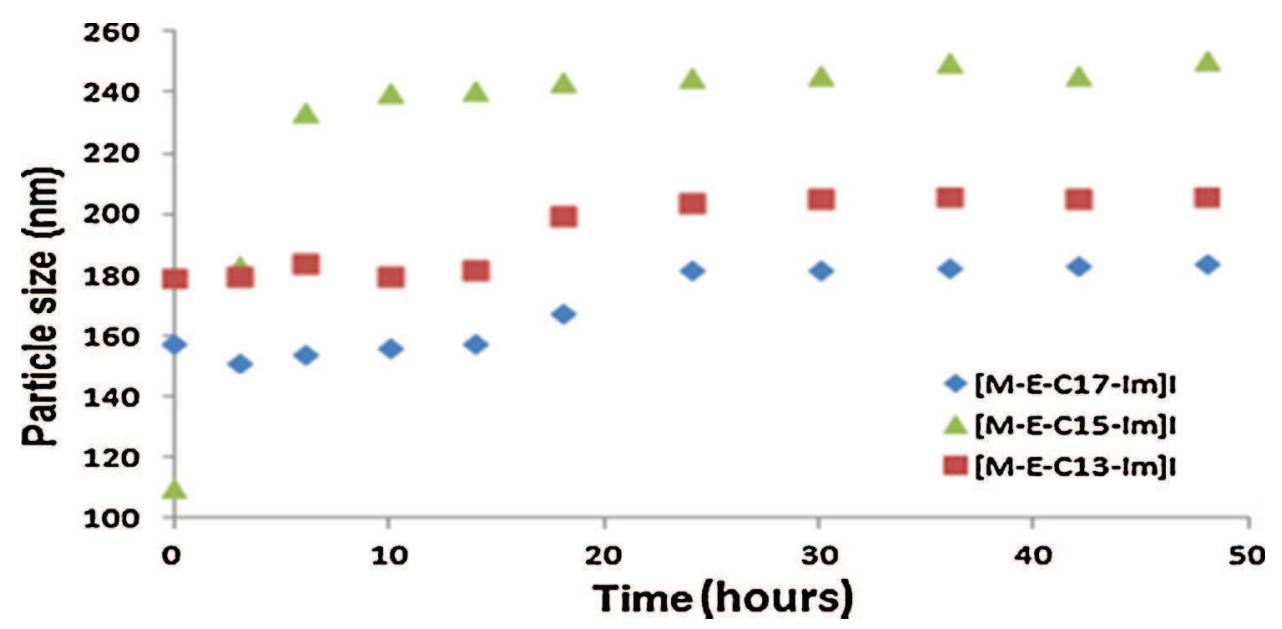

Fig. 10. Particle size of DWCNTs suspensions at $50 \mathrm{mg} / \mathrm{L}$ for the three ionic liquids at $1 \mathrm{mM}$. 

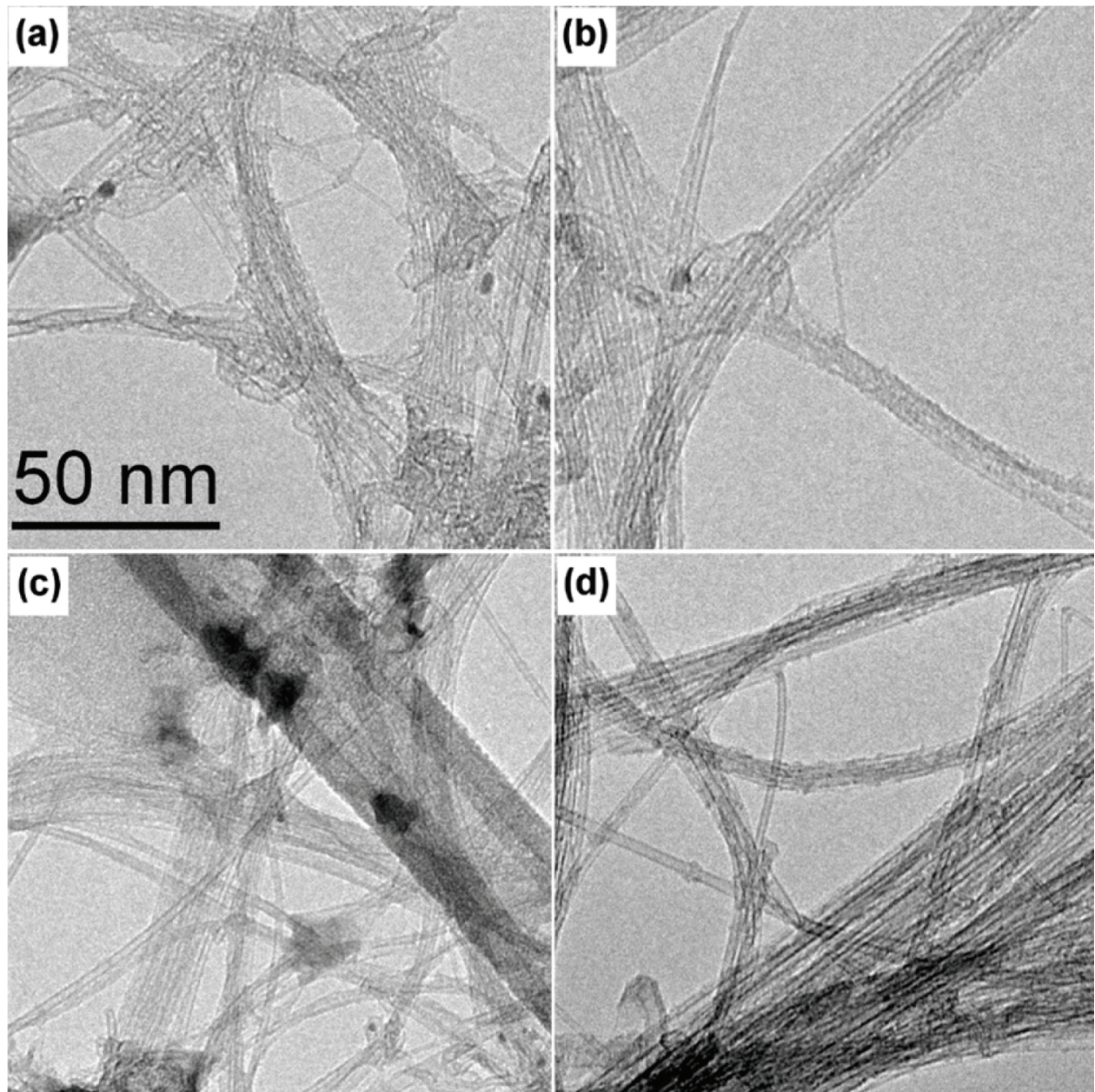

Fig. 11. TEM micrograph of DWCNT suspensions in deionized water at $50 \mathrm{mg} / \mathrm{L}$ with ionic liquid at $1 \mathrm{mM}$ (a) [M-E- $\left.\mathrm{C}_{13}-\mathrm{Im}\right] \mathrm{I}$, (b) [M-E-C $\left.\mathrm{C}_{15}-\mathrm{Im}\right] \mathrm{I}$, (c) [M-E- $\left.\mathrm{C}_{17}-\mathrm{Im}\right] \mathrm{I}$ and (d) deionized water alone. The scale bar $(50 \mathrm{~nm})$ is identical for all four images (same magnification).

Table 1

Zeta potential of DWCNT suspensions for the three ionic liquids (1 mM)

\begin{tabular}{ll}
\hline DWCNT suspensions with ionic liquid & Zeta potential $(\mathrm{mV})$ \\
\hline$\left[\mathrm{M}-\mathrm{E}-\mathrm{C}_{17}-\mathrm{Im}\right] \mathrm{I}$ & 60.6 \\
{$\left[\mathrm{M}-\mathrm{E}-\mathrm{C}_{15}-\mathrm{Im}\right] \mathrm{I}$} & 66.0 \\
{$\left[\mathrm{M}-\mathrm{E}-\mathrm{C}_{13}-\mathrm{Im}\right] \mathrm{I}$} & 45.0 \\
\hline
\end{tabular}

[M-E- $\left.\mathrm{C}_{17}-\mathrm{Im}\right] \mathrm{I}$. These values are however significantly higher than the zeta potential measured for [M-E- $\left.\mathrm{C}_{13}-\mathrm{Im}\right] \mathrm{I}$ in the same experimental conditions.

We were able to stabilize $50 \mathrm{mg} / \mathrm{L}$ of DWCNTs using a $50 \mathrm{mg} / \mathrm{L}$ of imidazolium-based ionic liquids compared to using $1000 \mathrm{mg} / \mathrm{L}$ of ionic liquid-type Gemini imidazolium for suspending $200 \mathrm{mg} / \mathrm{L}$ of MWCNTs [25].

The variation of the viscosity versus shear rate for the three ionic liquids and the DWCNT suspensions with the three ionic liquids is shown in Fig. 9. We have observed a low viscosity of the DWCNT suspensions with the three ionic liquids; this low viscosity can be explained by better charge repulsion between hydrophobic groups (the hydrocarbon chains) oriented along CNTs, when the hydrophilic heads are directed towards the aqueous phase, which prevents the agglomeration of the CNT $[17,56,57]$.

In order to demonstrate the stability through time of the DWCNT suspensions, size measurements of dispersed colloids were performed by the technique of static light diffusion. For this purpose, suspensions of carbon nanotubes were prepared with the three ionic liquids at $1 \mathrm{mM}$ as stabilizers. The sizes were measured for $48 \mathrm{~h}$ at regular time intervals (Fig. 10).

Measurements of particle size for the three suspensions of DWCNTs with each ionic liquid clearly show that CNTs are in the form of very small agglomerates with an average diameter between 150 and $250 \mathrm{~nm}$. We measured monomodal particle size distributions and a polydispersity index of 0.068 (the value of this index gives information about monodisperse systems, for which the index should be between 0.05 and 0.08 ). The size of the agglomerates in the suspensions of DWCNTs was practically stable during the $48 \mathrm{~h}$ of measurement and especially after $20 \mathrm{~h}$.

Transmission electron microscope (JEOL 1400) images of DWCNTs suspensions prepared with three ionic liquids, as well as the ones prepared with deionized water alone, are shown in Fig. 11. These images show that the three DWCNTs samples stabilized by ionic liquids formed smaller bundles compared to DWCNTs in deionized water alone. Therefore, the use of ionic liquids limited the agglomeration of DWCNTs. However, it is important to note that TEM observations were performed after drying the samples on TEM grids, so the images are probably not showing the real situation in the suspensions in the presence of liquid (agglomeration upon drying during sample preparation).

Finally, DWCNTs have a morphology very close to SWCNTs and share with them the ability to from long and flexible bundles. In our DWCNTs samples, the bundles are not very large (typically 20-30 nm maximum) and the samples contain many individual (or at least individual part of their length). However, they are the first 
multi-walled carbon nanotubes of the series and thus also share with larger MWCNTs the fact that the outer wall protects all the inner ones. As the interaction with a surfactant molecule is taking place only at the interface, the outer wall is the only to be concerned. DWCNTs are thus at the frontier between SWCNTs and MWCNTs in general and for this reason we can expect that the results of this study can extrapolated to all other kinds of CNTs, as long as they from bundles (which is still the case for many kinds of MWCNTs). However, it is clear that results may not be extrapolated to much shorter and individual CNTs, which could occur either intentionally if cutting procedures are applied (SWCNTs) or even unintentionally in the case of too strong sonication conditions for most MWCNTs.

\section{Conclusion}

Imidazolium-based ionic liquids 1-methyl-(1-ethanol)-2-alkylimidazoline ([M-E- $\left.C_{n}-\mathrm{Im}\right] \mathrm{I}, n=13,15$ and 17 ) were synthesized from the corresponding natural fatty acids and shown to be able to effectively suspend carbon nanotubes in water, even at very low concentration $(1 \mathrm{mM})$, for a period of more than a month. Quality of suspension was evidenced by optical density measurement, of zeta potential, particle size and TEM. The results of these analyses evidenced that we obtained stable suspensions, and also managed to partially de-bundle the DWCNTs. Comparing the dispersing strength of the three ionic liquids, we found that the dispersibility increased with increasing the length of the hydrocarbon chain, which is explained by the increased hydrophobic interactions between the hydrocarbon chain and DWCNTs. In addition, the suspensions of DWCNTs with ionic liquids had a viscosity similar to that of water, which is suitable for interaction with biological environments. Moreover, these results encourage the suspension of DWCNTs using imidazolium-based ionic liquids, for possible application in the study of toxicity/ecotoxicity of carbon nanotubes, thanks to their expected low intrinsic toxicity (which is however still to be measured for our series of new compounds).Acknowledgments

The authors express their sincere thanks to the Ministry of High Education and Scientific Research (Algeria) and the French Ministry of Foreign and European Affairs for financial support of PHC-TASSILI 10MDU797 project.

\section{References}

[1] S. Iijima, Helical microtubules of graphitic carbon, Nature 354 (1991) 56-58.

[2] A. Peigney, C. Laurent, E. Flahaut, R.R. Bacsa, A. Rousset, Specific surface area of carbon nanotubes and bundles of carbon nanotubes, Carbon 39 (2001) $507-514$

[3] S. Roche, Carbon nanotubes: exceptional mechanical and electronic properties, Ann. Chim. Sci. Matér. 25 (2000) 529-532.

[4] L.A. Girifalco, M. Hodak, R.S. Lee, Carbon nanotubes, buckyballs, ropes, and a universal graphitic potential, Phys. Rev. B 62 (2000) 13104-13110.

[5] E.V. Basiuk, V.A. Basiuk, V. Meza-Laguna, F.F. Contreras-Torres, M. Martínez, A Rojas-Aguilar, M. Salerno, G. Zavala, A. Falqui, R. Brescia, Solvent-free covalent functionalization of multi-walled carbon nanotubes and nanodiamond with diamines: looking for cross-linking effects, Appl. Surf. Sci. 259 (2012) 465-476.

[6] B.A. Kakade, V.K. Pillai, An efficient route towards the covalent functionalization of single walled carbon nanotubes, Appl. Surf. Sci. 254 (2008) 4936-4943.

[7] G. Xu, B. Zhu, Y. Han, Z. Bo, Covalent functionalization of multi-walled carbon nanotube surfaces by conjugated polyfluorenes, Polymer 48 (2007) 7510-7515.

[8] C. Hu, H. Liao, F. Li, J. Xiang, W. Li, S. Duo, M. Li, Noncovalent functionalization of multi-walled carbon nanotubes with siloxane polyether copolymer, Mater. Lett. 62 (2008) 2585-2588.

[9] A. Zhang, M. Tang, J. Luan, J. Li, Noncovalent functionalization of multi-walled carbon nanotubes with amphiphilic polymers containing pyrene pendants, Mater. Lett. 67 (2012) 283-285.

[10] L. Vaisman, H.D. Wagner, G. Marom, The role of surfactants in dispersion of carbon nanotubes, Adv. Colloid Interface Sci. 128-130 (2006) 37-46.

[11] M. Zhang, L. Su, L. Mao, Surfactant functionalization of carbon nanotubes (CNTs) for layer-by-layer assembling of CNT multi-layer films and fabrication of gold nanoparticle/CNT nanohybrid, Carbon 44 (2006) 276-283.

[12] A.L. Alpatova, W. Shan, P. Babica, B.L. Upham, A.R. Rogensues, S.J. Masten, E. Drown, A.K. Mohanty, E.C. Alocilja, V.V. Tarabara, Single-walled carbon nanotubes dispersed in aqueous media via non-covalent functionalization: effect of dispersant on the stability, cytotoxicity, and epigenetic toxicity of nanotube suspensions, Water Res. 44 (2010) 505-520

[13] D. Tasis, N. Tagmatarchis, V. Georgakilas, M. Prato, Soluble carbon nanotubes, Chem. Eur. J. 9 (2003) 4001-4008.

[14] L. Liu, K.C. Etika, K.-S. Liao, L.A. Hess, D.E. Bergbreiter, J.C. Grunlan, Comparison of covalently and noncovalently functionalized carbon nanotubes in epoxy, Macromol. Rapid Commun. 30 (2009) 627-632.

[15] H. Wang, Dispersing carbon nanotubes using surfactants, Curr. Opin. Colloid Interface Sci. 14 (2009) 364-371.

[16] M. Bassiouk, V.A. Basiuk, E.V. Basiuk, E. Álvarez-Zauco, M. Martínez-Herrera, A. Rojas-Aguilar, I. Puente-Lee, Noncovalent functionalization of single-walled carbon nanotubes with porphyrins, Appl. Surf. Sci. 275 (2013) 168-177.

[17] A. Skender, A. Hadj-Ziane-Zafour, E. Flahaut, Chemical functionalization of Xanthan gum for the dispersion of double-walled carbon nanotubes in water, Carbon 62 (2013) 149-156.

[18] H. Sato, M. Sano, Characteristics of ultrasonic dispersion of carbon nanotubes aided by antifoam, Colloids Surf. A: Physicochem. Eng. Asp. 322 (2008)103-107.

[19] I. Schwyzer, R. Kaegi, L. Sigg, A. Magrez, B. Nowack, Influence of the initial state of carbon nanotubes on their colloidal stability under natural conditions, Environ. Pollut. 159 (2011) 1641-1648.

[20] C. Hu, C. Yang, S. Hu, Hydrophobic adsorption of surfactants on water-soluble carbon nanotubes: a simple approach to improve sensitivity and antifouling capacity of carbon nanotubes-based electrochemical sensors, Electrochem. Commun. 9 (2007) 128-134

[21] P.S. Goh, B.C. Ng, A.F. Ismail, M. Aziz, S.M. Sanip, Surfactant dispersed multiwalled carbon nanotube/polyetherimide nanocomposite membrane, Solid State Sci. 12 (2010) 2155-2162.

[22] R. Rastogi, R. Kaushal, S.K. Tripathi, A.L. Sharma, I. Kaur, L.M. Bharadwaj, Comparative study of carbon nanotube dispersion using surfactants, J. Colloid Interface Sci. 328 (2008) 421-428.

[23] H.T. Ham, Y.S. Choi, I.J. Chung, An explanation of dispersion states of singlewalled carbon nanotubes in solvents and aqueous surfactant solutions using solubility parameters, J. Colloid Interface Sci. 286 (2005) 216-223.

[24] I. Madni, C.-Y. Hwang, S.-D. Park, Y.-H. Choa, H.-T. Kim, Mixed surfactant system for stable suspension of multiwalled carbon nanotubes, Colloids Surf. A: Physicochem. Eng. Asp. 358 (2010) 101-107.

[25] Y. Liu, L. Yu, S. Zhang, J. Yuan, L. Shi, L. Zheng, Dispersion of multiwalled carbon nanotubes by ionic liquid-type Gemini imidazolium surfactants in aqueous solution, Colloids Surf. A: Physicochem. Eng. Asp. 359 (2010) 66-70.

[26] A. Di Crescenzo, D. Demurtas, A. Renzetti, G. Siani, P. De Maria, M. Meneghetti, M. Prato, A. Fontana, Disaggregation of single-walled carbon nanotubes (SWNTs) promoted by the ionic liquid-based surfactant 1-hexadecyl-3-vinylimidazolium bromide in aqueous solution, Soft Matter 5 (2009) 62-66.

[27] J. Jiao, H. Zhang, L. Yu, X. Wang, R. Wang, Decorating multi-walled carbon nanotubes with Au nanoparticles by amphiphilic ionic liquid self-assembly, Colloids Surf. A: Physicochem. Eng. Asp. 408 (2012) 1-7.

[28] F. Lu, S. Zhang, L. Zheng, Dispersion of multi-walled carbon nanotubes (MWCNTs) by ionic liquid-based phosphonium surfactants in aqueous solution, J. Mol. Liq. 173 (2012) 42-46

[29] H.B. Kim, J.S. Choi, S.T. Lim, H.J. Choi, H.S. Kim, Preparation and nanoscopic internal structure of single-walled carbon nanotube-ionic liquid gel, Synth. Met. 154 (2005) 189-192.

[30] T. Aida, T. Fukushima, Soft materials with graphitic nanostructures, Philos. Trans. R. Soc. A: Math. Phys. Eng. Sci. 365 (2007) 1539-1552.

[31] S.H. Hong, T.T. Tung, L.K.H. Trang, T.Y. Kim, K.S. Suh, Preparation of single-walled carbon nanotube (SWNT) gel composites using poly(ionic liquids), Colloid Polym. Sci. 288 (2010) 1013-1018.

[32] C. Li, L. Gu, J. Tong, J. Maier, Carbon nanotube wiring of electrodes for highrate lithium batteries using an imidazolium-based ionic liquid precursor as dispersant and binder: a case study on iron fluoride nanoparticles, ACS Nano 5 (2011) 2930-2938.

[33] L. Lu, B. Liu, C. Liu, G. Xie, Amperometric immunosensor for myeloperoxidase in human serum based on a multi-wall carbon nanotubes-ionic liquid-cerium dioxide film-modified electrode, Bull. Kor. Chem. Soc. 31 (2010) 3259-3264.

[34] X. Pei, Y.H. Yan, L. Yan, P. Yang, J. Wang, R. Xu, M.B. Chan-Park, A magnetically responsive material of single-walled carbon nanotubes functionalized with magnetic ionic liquid, Carbon 48 (2010) 2501-2505.

[35] J. Yang, Z. Zhang, D. Zhang, Y. Li, Quantitative analysis of the ( $\mathrm{n}, \mathrm{m})$ abundance of single-walled carbon nanotubes dispersed in ionic liquids by optical absorption spectra, Mater. Chem. Phys. 139 (2013) 233-240.

[36] M. Zhao, Y. Gao, L. Zheng, Lyotropic liquid crystalline phases formed in binary mixture of 1-tetradecyl-3-methylimidazolium chloride/ethylammonium nitrate and its application in the dispersion of multi-walled carbon nanotubes, Colloids Surf. A: Physicochem. Eng. Asp. 369 (2010) 95-100.

[37] B. Dong, Y. Su, Y. Liu, J. Yuan, J. Xu, L. Zheng, Dispersion of carbon nanotubes by carbazole-tailed amphiphilic imidazolium ionic liquids in aqueous solutions, J. Colloid Interface Sci. 356 (2011) 190-195.

[38] J. Wang, H. Chu, Y. Li, Why single-walled carbon nanotubes can be dispersed in imidazolium-based ionic liquids, ACS Nano 2 (2008) 2540-2546.

[39] N. Madria, T.A. Arunkumar, N.G. Nair, A. Vadapalli, Y.-W. Huang, S.C. Jones, V.P. Reddy, Ionic liquid electrolytes for lithium batteries: synthesis, electrochemical, and cytotoxicity studies, J. Power Sources 234 (2013) 277-284.

[40] S.N. Riduan, Y. Zhang, Imidazolium salts and their polymeric materials for biological applications, Chem. Soc. Rev. 42 (2013) 9055-9070.

[41] R. Biczak, B. Pawłowska, P. Bałczewski, P. Rychter, The role of the anion in the toxicity of imidazolium ionic liquids, J. Hazard. Mater. 274 (2014) 181-190. 
[42] W. Gouveia, T.F. Jorge, S. Martins, M. Meireles, M. Carolino, C. Cruz, T.V. Almeida, M.E.M. Araújo, Toxicity of ionic liquids prepared from biomaterials, Chemosphere 104 (2014) 51-56.

[43] E. Flahaut, R. Bacsa, A. Peigney, C. Laurent, Gram-scale CCVD synthesis of double-walled carbon nanotubes, Chem. Commun. 9 (2003) 1442-1443.

[44] S.-H. Yoo, Y.-W. Kim, K. Chung, S.-Y. Baik, J.-S. Kim, Synthesis and corrosion inhibition behavior of imidazoline derivatives based on vegetable oil, Corros. Sci. 59 (2012) 42-54.

[45] S.F. Wang, T. Furuno, Z. Cheng, Synthesis of 1-hydroxyethyl-2-alkyl-2imidazoline and its derivative sulfonate amphoteric surfactant from tall oil fatty acid, J. Wood Sci. 49 (2003) 371-376.

[46] S. Sharma, S. Gangal, A. Rauf Convenient one-pot synthesis of novel 2 substituted benzimidazoles, tetrahydrobenzimidazoles and imidazoles and evaluation of their in vitro antibacterial and antifungal activities, Eur. J. Med. Chem. 44 (2009) 1751-1757.

[47] F. Mouchet, P. Landois, E. Sarremejean, G. Bernard, P. Puech, E. Pinelli, E. Flahaut, L. Gauthier, Characterisation and in vivo ecotoxicity evaluation of double-wal carbon nanotubes in larvae of the amphibian Xenopus laevis, Aquat. Toxicol. 87 (2008) 127-137.

[48] F. Bourdiol, F. Mouchet, A. Perrault, I. Fourquaux, L. Datas, C. Gancet, J.-C Boutonnet, E. Pinelli, L. Gauthier, E. Flahaut, Biocompatible polymer-assisted dispersion of multi walled carbon nanotubes in water, application to the investigation of their ecotoxicity using Xenopus laevis amphibian larvae, Carbon 54 tigation of their

[49] S. Azoubel, S. Magdassi, The formation of carbon nanotube dispersions by high pressure homogenization and their rapid characterization by analytical centrifuge, Carbon 48 (2010) 3346-3352.
[50] C. Richard, F. Balavoine, P. Schultz, T.W. Ebbesen, C. Mioskowski, Supramolecular self-assembly of lipid derivatives on carbon nanotubes, Science 300 (2003) $775-778$.

[51] S. Utsumi, M. Kanamaru, H. Honda, H. Kanoh, H. Tanaka, T. Ohkubo, H. Sakai, M. Abe, K. Kaneko, RBM band shift-evidenced dispersion mechanism of singlewall carbon nanotube bundles with NaDDBS, J. Colloid Interface Sci. 308 (2007) 276-284.

[52] Y. Bai, D. Lin, F. Wu, Z. Wang, B. Xing, Adsorption of Triton X-series surfactants and its role in stabilizing multi-walled carbon nanotube suspensions, Chemosphere 79 (2010) 362-367.

[53] M.F. Islam, E. Rojas, D.M. Bergey, A.T. Johnson, A.G. Yodh, High weight fraction surfactant solubilization of single-wall carbon nanotubes in water, Nano Lett. 3 (2003) 269-273.

[54] B. Yu, F. Zhou, G. Liu, Y. Liang, W.T.S. Huck, W. Liu, The electrolyte switchable solubility of multi-walled carbon nanotube/ionic liquid (MWCNT/IL) hybrids, Chem. Commun. (2006) 2356-2358.

[55] J. Rausch, R.-C. Zhuang, E. Mäder, Surfactant assisted dispersion of functional ized multi-walled carbon nanotubes in aqueous media, Compos. A: Appl. Sci. Manuf. 41 (2010) 1038-1046.

[56] O. Osazuwa, K. Petrie, M. Kontopoulou, P. Xiang, Z. Ye, A. Docoslis, Characterization of non-covalently, non-specifically functionalized multi-wall carbon nanotubes and their melt compounded composites with an ethylene-octene copolymer, Compos. Sci. Technol. 73 (2012) 27-33.

[57] F.-C. Li, J.-C. Yang, W.-W. Zhou, Y.-R. He, Y.-M. Huang, B.-C. Jiang, Experimental study on the characteristics of thermal conductivity and shear viscosity of viscoelastic-fluid-based nanofluids containing multiwalled carbon nanotubes, Thermochim. Acta 556 (2013) 47-53. 